\title{
O ENSINO DE LÍNGUA PORTUGUESA PARA SURDOS NA ESCOLA “INCLUSIVA": PRINCÍPIOS E PRÁTICAS*
}

Lucineide Machado Pinheiro

\section{Introdução}

O ensino de Língua Portuguesa para surdos esteve centrado durante muito tempo na abordagem oralista, privilegiando assim o ensino da modalidade oral da língua, por meio da qual os estudantes deveriam se comunicar e aprender os conteúdos. Segundo esta abordagem, a língua é concebida como um código formado por prescrições supostamente voltadas ao processo de ensino-aprendizagem. Portanto, para usar a língua de maneira considerada adequada, o estudante deveria administrar e dominar o código, isto é, as suas regras (KOCH, 2001 apud PEREIRA, 2014). De modo paralelo, a língua de sinais, compreendida de maneira equivocada como gestos rudimentares e/ou mímica, era proibida de ser utilizada pelos surdos nas escolas. (GUARINELLO, 2007).

A despeito de parte dos estudantes demonstrar bom domínio dos eixos $^{1}$ de ensino de língua portuguesa, muitos aprenderam a usar a língua de forma fragmentada e sem que, principalmente, desenvolvessem uma produção escrita como expressão da compreensão e reflexão de texto, em decorrência da adoção da concepção de língua como código, "[...] como se os estudantes aprendessem a língua de fora para dentro, sem fazer uma reflexão sobre o seu funcionamento" (PEREIRA, 2015, p. 02).

Nesse contexto, as dificuldades apresentadas pelos surdos na compreensão da língua portuguesa passaram a ser atribuídas à surdez, e não à abordagem de ensino utilizada. Autores como Fernandes (1998), Pereira (2009) e Pinheiro (2018) atestam que os obstáculos encontrados pelos surdos na aprendizagem da língua portuguesa não podem ser imputados à surdez,

\footnotetext{
*DOI - 10.29388/978-65-86678-60-4-0-f.223-246

${ }^{1}$ Segundo a BNCC (2016, p. 71), os eixos de ensino de Língua Portuguesa são "[...] oralidade, leitura/escuta, produção (escrita e multissemiótica) e análise linguística/semiótica (que envolve conhecimentos linguísticos - sobre o sistema de escrita, o sistema da língua e a norma-padrão -, textuais, discursivos e sobre os modos de organização e os elementos de outras semioses)".
} 
pois resultam da abordagem empregada nas escolas, que não atende às especificidades linguísticas e de aprendizagem desses alunos. A abordagem utilizada, tanto para alunos surdos como para ouvintes, não cumpre as finalidades do ensino de língua no que tange à compreensão de texto e de mundo voltada à formação humana.

Devido ao insucesso da abordagem oralista nas práticas de ensino de língua portuguesa, retratado nas complicações geradas para o processo de ensino-aprendizagem dos surdos, bem como nas reivindicações da comunidade surda para que a língua de sinais fosse aceita nas escolas, em 1970 a abordagem da comunicação total começou a ser utilizada com o propósito de ensinar a língua portuguesa aos surdos e viabilizar a comunicação entre estes e os ouvintes (PEREIRA, 2014). A comunicação total sugere "[...] o uso de gestos naturais, da língua de sinais, do alfabeto digital, da expressão facial, da fala e dos aparelhos de amplificação sonora para transmitir linguagem, vocabulário, conceitos e ideias" (GUARINELLO, 2007, p. 31).

Apesar da rápida disseminação, a abordagem da comunicação total não produziu os resultados esperados em relação ao desempenho acadêmico dos surdos, em razão de ser impossível o uso simultâneo da língua de sinais e da língua majoritária (GUARINELLO, 2007).

Com o objetivo de contemplar as particularidades linguísticas e de aprendizagem dos surdos no processo de ensino-aprendizagem da língua portuguesa, além de contrapor a ideia de que o aprendizado da língua majoritária como primeira língua é que possibilitaria ao surdo desenvolver-se cognitivamente, no final da década de 1970, emerge no Brasil a abordagem bilíngue, também em consequência das reivindicações do movimento surdo em prol do reconhecimento da língua de sinais e pela liberdade de seu uso dentro e fora do ambiente educacional. Conceituada por Fernandes e Correia (2015) como a diretriz dos modelos educacionais, a abordagem bilíngue considera a Língua Brasileira de Sinais (Libras) $^{2}$ como a primeira língua do

\footnotetext{
${ }^{2}$ Neste trabalho, escolhemos a grafia Libras (com a primeira letra em maiúscula), à semelhança de Brito (2013, p. 12), porque entendemos "[...] que se trata do acrônimo de língua brasileira de sinais e os acrônimos com quatro letras ou mais têm apenas a inicial maiúscula quando são pronunciados como uma única palavra. $\mathrm{O}$ uso da grafia Libras, além de ser atualmente a mais difundida, é também compatível com a maior parte da legislação de reconhecimento e regulamentação dessa língua"; embora existam variações, tais como LIBRAS, LSB, libras e não haja um consenso na literatura a respeito da grafia.
} 
surdo e a língua majoritária - no caso do Brasil, a língua portuguesa -, sua segunda língua.

A abordagem bilíngue "[...] preconiza que o surdo deve ser exposto o mais precocemente possível a uma língua de sinais, identificada como uma língua passível de ser adquirida por ele sem que sejam necessárias condições especiais de 'aprendizagem'”. (LACERDA, 2000, p. 73). Além disso, recomenda ainda que a língua portuguesa, em sua modalidade oral e/ou escrita, seja ensinada com base nos conhecimentos da língua de sinais (LACERDA, 2000); isto é, a língua de sinais deve se constituir como língua de comunicação e instrução nas práticas pedagógicas (QUADROS, 1997). Dessa forma, trata-se de uma abordagem que possibilita que o surdo se desenvolva plenamente tanto em termos de linguagem quanto de cognição.

Segundo Matos (2017), a abordagem bilíngue pode ser desenvolvida por meio de dois modelos: simultâneo ou consecutivo. No bilinguismo simultâneo, o ensino da segunda língua realiza-se de forma síncrona ao ensino da primeira, porém em momentos diferentes e com interlocutores distintos. No caso da criança surda, o ensino da língua de sinais deve, preferencialmente, efetivar-se por meio de uma pessoa surda, e o da língua portuguesa com uma pessoa ouvinte, tão logo a surdez seja diagnosticada (GUARINELLO, 2007). Esse modelo de bilinguismo tem sido bastante questionado por alguns autores (QUADROS, 1997; MATOS, 2017); segundo propõe Vygotsky ([1934] 2001), em razão da necessidade do domínio de uma primeira língua que organize e constitua o pensamento para que o processo de ensino-aprendizagem da segunda aconteça de forma plena. No bilinguismo consecutivo, somente quando a criança surda tem o domínio da língua de sinais é que ocorre o ensino da segunda língua. Se considerarmos esse tipo de bilinguismo como proposta-modelo, uma vez que pressupõe o domínio da primeira língua pela criança, temos de ponderar o fato de que muitos surdos nascem em famílias ouvintes que desconhecem a língua de sinais (CAMPOS, 2017); logo, tanto o acesso a esta língua quanto as experiências culturais, às quais deveriam ter acesso, são impossibilitadas devido aos espaços monolíngues nos quais convivem. Nesse sentido, torna-se fundamental oportunizar o aprendizado da língua de sinais aos familiares da criança surda já no decurso dos seus primeiros anos de vida. 
No contexto educacional brasileiro, a proposta bilíngue ganhou força na década 1990, com a consolidação - apenas em termos legais - da inclusão escolar, influenciada pela Conferência Mundial sobre Necessidades Educacionais Especiais: Acesso e Qualidade (UNESCO, 1994), da qual resultou a Declaração de Salamanca ${ }^{3}$. A inclusão escolar pauta-se no princípio de que todas as pessoas, independente de quaisquer condições físicas, sociais e linguísticas, têm direito a receber educação de qualidade em escolas comuns. Para tanto, orienta que as escolas, as políticas públicas e o sistema educacional, de modo geral, adequem-se em direção às particularidades dos estudantes. Em relação aos surdos, a Declaração de Salamanca propõe que:

[...] políticas educacionais deveriam levar em total consideração as diferenças individuais. A importância da linguagem de signos [língua de sinais] como meio de comunicação entre os surdos, por exemplo, deveria ser reconhecida e provisão deveria ser feita no sentido de garantir que todas as pessoas tenham acesso à educação em sua língua nacional de signos [sinais] (UNESCO, 1994).

Embora a inclusão escolar tenha corroborado com a educação de surdos ao se referir à abordagem bilíngue em suas proposições, foi somente a partir do século XXI, com o reconhecimento da língua de sinais como língua, mais precisamente, por meio da Lei Federal n.o 10.436/02 (BRASIL, 2002) e da promulgação do Decreto Federal n. $5.626 / 05$ (BRASIL, 2005), que esta proposta passou a ser amplamente discutida.

O Decreto $\mathrm{n}$. 0 5.626/05, em seu artigo art. 22, declara que as instituições de ensino, no que concerne à proposta inclusiva, devem assegurar aos alunos surdos escolas e classes bilíngues, com professores bilíngues na Educação Infantil e nos anos iniciais do Ensino Fundamental; e escolas comuns, com acessibilidade linguística promovida por tradutores e intérpretes de Libras nos anos finais do Ensino Fundamental e no Ensino Médio. O documento define escolas ou classes de educação bilíngue como espaços onde "[...] a Libras e a modalidade escrita da Língua Portuguesa sejam línguas de instrução utilizadas no desenvolvimento de todo o processo educativo (BRASIL, 2005, art. 22, incisos I, II).

\footnotetext{
${ }^{3}$ Documento norteador das ações inclusivas, do qual o Brasil é signatário.
} 
De modo contrário, porém, ao que propõe o decreto $\mathrm{n}$. 9 5.626/05, o monolinguismo da Língua Portuguesa ainda prevalece nas práticas pedagógicas em escolas comuns cujo alunado é formado de surdos e ouvintes. A despeito da Declaração de Salamanca e da abordagem bilíngue preconizarem, desde 1990, que a educação dos surdos seja acessível em língua de sinais a fim de atender a especificidade linguística desses alunos, a política nacional de ensino-aprendizagem (BRASIL, 2017), embora tenha reorientado o ensino de Língua Portuguesa - a partir de discussões produzidas pela Linguística, fomentando uma mudança de perspectiva que, por sua vez, influenciou o modo de conceber a língua, a gramática, o texto e a frase (ANTUNES, 2009; MARCUSCHI, 2008), paradoxalmente, não contemplou as particularidades dos surdos em suas proposições.

Distanciando-se da concepção de língua como código, o ensino de Língua Portuguesa foi reorientado sob o fundamento do uso social da língua mediante a qual os indivíduos podem interagir com o mundo que os cerca, bem como desenvolver suas capacidades cognitivas e linguísticas (ANTUNES, 2009; MARCUSCHI, 2008). Ademais, passou a ser baseado no conhecimento da linguagem escrita e no desenvolvimento da leitura, fundamentais para a compreensão do conteúdo escolar de diferentes áreas. É por meio da leitura que o aluno acessa as informações do texto, atribui-lhe sentido e constrói conhecimento (PINHEIRO, 2018).

Ao se apoiar no uso social e no caráter comunicativo da língua portuguesa, a política nacional de ensino-aprendizagem estabelece como objetivos para o Ensino Fundamental a formação básica do cidadão mediante o “[...] pleno domínio da leitura, da escrita e do cálculo (BRASIL, 2017, p. 23). Para o Ensino Médio, destaca como finalidades os conhecimentos para que o cidadão continue aprendendo e se desenvolvendo, incentiva "[...] a formação ética e o desenvolvimento da autonomia intelectual e o pensamento crítico (BRASIL, 2017, p. 24). Para tanto, os conceitos de linguagem, discurso, texto e gramática devem fundamentar o ensino de Língua Portuguesa e orientar os professores no desenvolvimento de propostas significativas (MARCUSCHI, 2008; ANTUNES, 2009; PEREIRA, 2014).

A linguagem, ampla e diversificada, é o meio pelo qual as pessoas interagem socialmente de diferentes formas. Já a língua pode ser conceituada como "[...] atividade, como lugar de interação humana, de interlocução, entendida como espaço de produção de linguagem e de constituição de 
sujeitos" (PEREIRA, 2014, p. 148). A língua permite ao ser humano entender a realidade que o cerca por meio da compreensão dos significados culturais e históricos construídos e da forma como as pessoas interpretam os fatos sociais e a si mesmos (PINHEIRO, 2018).

Ao utilizarem a língua, as pessoas produzem discursos. Comunicam algo a um interlocutor, de uma determinada forma, com um objetivo específico e a partir das suas próprias concepções e visões de mundo. A competência discursiva, aqui caracterizada como a capacidade de utilizar a língua adequando-a semanticamente ao contexto de produção do texto oral ou escrito, incorpora a competência linguística e estilística.

Uma escola comprometida com a cidadania, ao organizar o ensino de língua portuguesa, precisa criar condições para o desenvolvimento da competência discursiva dos alunos, a qual pode se manifestar por meio de textos, sejam estes orais ou escritos. Segundo Antunes (2009, p. 52),

[...] o texto envolve uma teia de relações, de recursos, de estratégias, de operações, de pressupostos, que promovem a sua construção, que promovem seus modos de sequenciação, que possibilitam seu desenvolvimento temático, sua relevância informativo-contextual, sua coesão e sua coerência, enfim.

Nessa perspectiva, o texto constitui o ponto de partida e de chegada do processo de ensino-aprendizagem da língua portuguesa (GERALDI, 1993 apud PEREIRA, 2009), diferenciando-se, assim, das práticas tradicionais, nas quais o texto era tomado como pretexto para o ensino da gramática normativa, enquanto a palavra era considerada como elemento de aderência para a composição das sentenças e aspecto principal de análises gramaticais.

O desenvolvimento de pesquisas e a adoção da concepção sociointeracionista da linguagem provocou mudanças no ensino de língua portuguesa para ouvintes e surdos. $\mathrm{O}$ ensino deixou de seguir padrões fixos e os alunos passaram a ser inseridos em situações contextuais de uso da língua.

Assim, passou-se a entender a importância da interação dos estudantes surdos em práticas de uso social do português escrito; para isso a língua de sinais possibilita, entre outros pontos importantes, a construção de conhecimento de mundo e dos gêneros textuais, a atribuição de sentido à leitura de textos e à expressão escrita em língua portuguesa (MÜLLER, 2016, p.155). 
Em contextos de atividade, professores e colegas constituíam-se interlocutores e aprendiam a língua em funcionamento. A concepção sociointeracionista da linguagem sustenta o princípio de que, ao usarem a língua dessa forma, os alunos desenvolvem as habilidades requeridas ao exercício da cidadania e a imersão no mundo do trabalho. Quanto ao estudo da gramática e de seus elementos, a proposta é que este ocorra depois da compreensão do uso e funcionamento da língua, tendo como eixo central o texto (PINHEIRO, 2018).

Segundo Pereira (2014), em relação aos alunos surdos, o texto precisa ser trabalhado precipuamente em língua de sinais. "Para isso cabe ao professor traduzir os textos ou partes deles para a língua de sinais e vice-versa, bem como explicar e esclarecer aspectos sobre a construção dos textos" (PEREIRA, 2014, p. 149). Nesse sentido, pode-se recorrer à perspectiva contrastiva, por meio da qual as particularidades das línguas - língua portuguesa e Libras -, que as aproximam ou as distanciam, sejam discutidas, esclarecidas e estudadas. Assim, os alunos podem perceber como uma determinada ideia se expressa em ambas as línguas (PEREIRA, 2014).

A despeito do redirecionamento do ensino de língua portuguesa ter ocorrido com ênfase nas questões relacionadas à formação humana a partir da concepção sociointeracionista da linguagem, na prática, o ensino continuou pautado na abordagem de ensino de primeira língua para ouvintes, conforme pode ser constatado nas proposições da Lei de Diretrizes e Bases da Educação Nacional (LDBN) (BRASIL, 2017) e do Currículo do Estado de São Paulo Linguagens, Códigos e suas Tecnologias (SÃO PAULO, 2011) ${ }^{4}$. Tais documentos não fazem referência às abordagens diferenciadas para o ensino de Língua Portuguesa como segunda língua (L2) aos surdos, visando atender a especificidade linguística desses alunos. Do mesmo modo, a nova Base Nacional Comum Curricular - "[...] documento de caráter normativo que define o conjunto orgânico e progressivo de aprendizagens essenciais que todos os alunos devem desenvolver ao longo das etapas e modalidades da Educação Básica" (BNCC, 2016, p. 07) - não faz referência à abordagem bilíngue e à concepção sociointeracionista da linguagem nas práticas de ensino de Língua Portuguesa direcionada aos surdos, tampouco, à perspectiva contrastiva. -

\footnotetext{
${ }^{4}$ Esse documento "apresenta os princípios orientadores do currículo para uma escola capaz de promover as competências indispensáveis ao enfrentamento dos desafios sociais, culturais e profissionais do mundo contemporâneo" (SÃO PAULO, 2011, p. 09).
} 
Diante desse contexto, este estudo, derivado de uma pesquisa concluída de doutorado (PINHEIRO, 2018), objetiva abordar os princípios que norteiam o ensino de língua portuguesa para surdos em escolas "inclusivas" ${ }^{5}$, bem como verificar se a concepção sociointeracionista da linguagem e a abordagem bilíngue têm sido incorporadas na prática dos professores.

\section{Metodologia}

Situado na intersecção entre Educação, Psicologia Sócio-HistóricoCultural e Linguística Aplicada, este estudo apoia-se na Metodologia da Pesquisa Crítica de Colaboração (PCCol) (MAGALHÃES, 2006) e no Interacionismo Sociodiscursivo (ISD) (BRONCKART, 2006), que indica possibilidades de análise do conteúdo linguístico produzido pelos participantes nas interações estabelecidas.

Desenvolvida em instituições educacionais, a Pesquisa Crítica de Colaboração (PCCol) pressupõe a participação de todos os integrantes envolvidos com a pesquisa, quer sejam alunos, professores ou pesquisadores, de forma dialógica, com o objetivo de produzir mudanças no contexto investigado, mediante a análise e a perspectiva crítico-reflexiva sobre suas práticas. Nesse contexto, o pesquisador, ao figurar também como um participante, age conjuntamente por meio de intervenções colaborativas, com vistas à transformação das estruturas de pensamento e ação que concorrem para tensionar a problemática educacional.

A colaboração, conceito nodal na PCCol, ocorre quando o pesquisador estabelece um espaço para que os participantes observem a realidade investigada e, à luz de relações dialéticas negociadas, questionem os significados expressos nas ações e/ou nas palavras, bem como os interesses a que servem. Assim sendo, cabe ao pesquisador propiciar situações para que os participantes "[...] examinem suas ações à luz das negociações estabelecidas, como verdadeiros colaboradores que juntos analisam práticas, refletem criticamente e argumentam para a (des)construção de teorias [...] que realmente embasam as práticas da sala de aula, mas também as das negociações envolvidas" (MAGALHÃES, 2006, p. 152).

\footnotetext{
${ }^{5}$ Optamos por utilizar a palavra "inclusivas", entre aspas, porque entendemos que a inclusão escolar, de fato, não tem acontecido, caracterizando-se mais como um processo inclusivoexcludente.
} 
Denominado de Sessão Reflexiva (SR) por Magalhães (2006), o espaço criado pelo pesquisador ocorre, geralmente, após a observação videogravada da aula do professor. É um momento em que ambos refletem sobre a ação e sobre a reflexão na ação (SCHÖN, 1995), discutem os conceitos e significados veiculados na prática em sala de aula com base em teorias e buscam estratégias para modificar o curso das ações, visando uma transformação, processo que se dá na Zona de Desenvolvimento Proximal (ZDP), espaço definido por Vygotsky ([1934] 2009) como a distância entre o que conseguimos fazer sozinhos e o que fazemos com o apoio de outros, nossos pares. Isto posto, optamos por essa metodologia, porque nos dispusemos a atuar como pesquisadores-participantes, com o objetivo de colaborar na produção de transformações.

Vygotsky, na procura por um elemento de análise para a relação entre pensamento e linguagem, encontra o significado da palavra. Para ele, o significado é a unidade que reflete de forma mais simples esta relação. "O significado é uma unidade indecomponível de ambos os processos" (VYGOTSKY, [1934] 2009, p. 398). Não é um fenômeno só da linguagem ou do pensamento. A palavra só existe porque é constituída de significado. E este é construído pela própria palavra e internalizado, embora essa internalização seja um processo único e diferente para cada ser humano. É por isso que o autor difere significado e sentido, o último sendo particular, relativo ao pensamento de cada indivíduo. Com base em Vygotsky ([1934] 2009), Pinheiro e Fidalgo (2019, p. 05), afirmam que "[...] o sentido é um aspecto psicológico da fala. Uma forma de compreendermos a fala pelo viés psicológico, a partir da internalização dos significados socialmente construídos [...]".

Desenvolvemos a pesquisa em duas escolas "inclusivas", localizadas nas cidades de Osasco e Guarulhos, no Estado de São Paulo, em 2015 e 2016, respectivamente, com três professores de Língua Portuguesa - Suzana, Artur e Juliana - que lecionavam no 9 o ano do Ensino Fundamental, em salas em que havia alunos surdos matriculados e intérpretes de Libras. Realizamos quatro observações videogravadas de aulas de cada professor e, sequencialmente, quatro sessões reflexivas. Aplicamos entrevistas para conhecer o perfil dos participantes, bem como caracterizar sua formação acadêmica e profissional. Os dados gravados foram transcritos e analisados. Todos os nomes utilizados no trabalho são fictícios, de modo a proteger a identidade dos participantes. 
Como categorias de análise, recorremos ao Interacionismo Sociodiscursivo no que se refere ao contexto de produção e ao conteúdo temático, propostos por Bronckart (2006). O quadro abaixo retrata um exemplo de conteúdo temático em que o tema é retirado das perguntas de pesquisa, a categoria de sentido é derivada de Vygotsky e os exemplos são as falas dos participantes.

Quadro 01: Dificuldade em gramática atribuída aos surdos - dados da 1ạ. SR com Suzana

\begin{tabular}{|l|l|l|}
\hline \multicolumn{1}{|c|}{ TEMA } & \multicolumn{1}{|c|}{ SENTIDO } & \multicolumn{1}{c|}{ EXEMPLO } \\
\hline $\begin{array}{l}\text { Aspectos } \begin{array}{l}\text { curriculares de } \\
\text { Língua Portuguesa }\end{array} \\
\text { Dificuldade em } \\
\text { gramática atribuída } \\
\text { aos surdos }\end{array}$ & $\begin{array}{l}\text { SSuzana 1: [...] na realidade, aquela aula eu } \\
\text { nem iria ainda trabalhar gramática. Eu tava } \\
\text { como uma atividade em andamento, eu alterei } \\
\text { porque assim, eu queria te mostrar assim, a } \\
\text { dificuldade de trabalhar com eles a gramática } \\
\text { né? }\end{array}$ \\
\hline
\end{tabular}

Fonte: Pinheiro (2018, p. 319)

\section{Análise e discussão de dados}

O ensino de língua portuguesa foi redirecionado para a concepção sociointeracionista da linguagem. As prerrogativas legais e os marcos teóricos orientadores ensejaram novas práticas pedagógicas que garantem, precipuamente, a preparação docente para lecionar em salas em que há alunos surdos matriculados.

A despeito do que asseguram as políticas educacionais, as situações que despontam no cenário escolar evidenciam que os professores não recebem formação apropriada e, por isso, desconhecem como ensinar língua portuguesa para os alunos surdos; e estes, muitas vezes, permanecem sem aprender competências básicas de leitura e escrita que lhes possibilitariam acessar conteúdos e textos das demais disciplinas escolares.

Devido à precarização da formação, é comum os professores recorrerem às práticas tradicionais (PINHEIRO, 2018). Além disso, planejam e

\footnotetext{
${ }^{6}$ A transcrição dos dados foi desenvolvida com base nas normas encontradas em PRETI, D. Análise de textos orais. São Paulo: Humanitas,1999 e adaptadas pelos grupos de pesquisa ILCAE - Inclusão Linguística em Cenários de Atividades Educacionais e GEICS - Grupo de Estudos e Pesquisas sobre Identidade e Cultura Surda, da Universidade Federal de São Paulo (UNIFESP).
} 
constroem a aula com base na concepção de língua como código, em detrimento de um trabalho centrado no texto enquanto atividade discursiva, conforme demostra a primeira sessão reflexiva com o professor Artur, realizada após a observação videogravada da sua primeira aula de Língua Portuguesa.

Em sua primeira sessão reflexiva (quadro 02), o professor Artur parece compreender que, segundo a perspectiva de uso social da língua, o ensino deve pautar-se numa abordagem que considere a Língua Portuguesa enquanto instrumento de comunicação (prática discursiva), divergindo, portanto, de sua própria prática adotada em sala de aula, ao usar o texto como "pretexto" para o ensino da gramática descontextualizada e à aplicação de atividades, mesmo que pareça não perceber tal contradição.

Quadro 02: Texto como pretexto para ensinar gramática - dados da 1ạ. SR com o professor Artur

\begin{tabular}{|c|c|c|}
\hline TEMA & SENTIDO & EXEMPLO \\
\hline $\begin{array}{c}\text { Aspectos } \\
\text { curriculares de } \\
\text { Língua } \\
\text { Portuguesa }\end{array}$ & $\begin{array}{c}\text { Texto como } \\
\text { pretexto para ensinar } \\
\text { gramática }\end{array}$ & $\begin{array}{l}\text { Artur 2: A intervenção que eu queria } \\
\text { fazer com eles [...] que eu tentei te mostrar, } \\
\text { que a língua, ela tem as variantes. Porque } \\
\text { atualmente já tem essa questão de você não } \\
\text { ficar mais centralizado na parte gramatical, } \\
\text { né? Hoje em dia se vê mais o ensino de língua } \\
\text { como:: um instrumento de comunicação, né, } \\
\text { do que como instrumento de você fazê-los } \\
\text { conhecer a gramática, de fato. Então sempre } \\
\text { que eu trabalho, eu procuro ter esse } \\
\text { estímulo, trazer um texto. Então naquele dia } \\
\text { eu trouxe um texto que... é :: fazia uma } \\
\text { abordagem da língua de uma variante é... } \\
\text { mais informal, pra que eles pudessem ter } \\
\text { essa comparação. O que eu queria que eles } \\
\text { percebessem é que mesmo dentro da Língua } \\
\text { Portuguesa existe uma variante que é formal } \\
\text { e que eles precisam conhecer, e uma variante } \\
\text { que é informal [...]. }\end{array}$ \\
\hline
\end{tabular}

Fonte: Pinheiro (2018, p. 295)

Na sequência didática da primeira aula de Artur, não se desenvolve um trabalho efetivo por meio do texto (letra de música), capaz de instigar os alunos a adentrarem no universo da leitura e construírem sentidos e 
significados. A organização da aula consistiu: (1) na explanação pelo professor sobre concordância verbal; (2) na leitura da letra da música e (3) na aplicação de um exercício para que os alunos adequassem a letra da música à linguagem formal (dados da gravação da 1. a aula). Apesar de o professor teoricamente saber que "hoje em dia se vê mais o ensino de língua como um instrumento de comunicação", sua prática denota que desconhece como o ensino de Língua Portuguesa pode ser construído por meio dessa abordagem.

Ao usar a letra da música sem atentar para o interesse e a realidade dos alunos (quadro 03), e dividi-los em grupo para a realização da atividade, Artur considera concretizar uma prática de uso funcional e comunicativo da língua; quando, na verdade, a forma como o professor constrói a aula assentase em uma prática tradicional. Dessa forma, o ensino não está voltado para a formação de leitores críticos e participativos, mas para o treino de elementos gramaticais descontextualizados.

Quadro 03: Informação sobre a letra da música - dados da 1. a aula do professor Artur

Artur 20: Gente, gente, aqui ó: nós vamos trabalhar conforme sempre eu faço com vocês, com letra de música. Então é o seguinte...

Artur 21: Essa música chama-se Inútil [...].

Artur 22: Não é do tempo de vocês.

Fonte: Pinheiro (2018, p. 296)

A prática tradicional de ensino de língua portuguesa foi também observada na aula de Juliana. Em sua primeira aula (quadro 04), a professora solicita que os alunos utilizem o texto intitulado "Tô com fome", presente no livro didático, e sublinhem os substantivos, os adjetivos e as locuções adjetivas. Inicia a aula com foco direto nas questões gramaticais e recorre ao texto apenas para aplicar exercícios. Não há um trabalho efetivo de leitura, análise e compreensão de texto, logo, torna-se inviável formar leitores competentes de modo que possam interpretar a realidade e atuar sobre esta, com vistas a modificá-la. 
Quadro 04: Uso do texto como pretexto para o ensino da gramática - dados da 1. . aula da professora Juliana

Juliana 1: [...]. Vocês vão fazer a atividade do livro [...]. Então na página 129 vocês tinham... o texto "Tô com fome", tá? [...]. Vocês vão pegar esse texto, vão ler, tá, [...] e aí vocês vão pegar, sublinhar [...] a lápis aqui no próprio livro [...]. Bom, sublinhando as palavras significativas, os substantivos, vocês vão sublinhar todos, tá? E depois vocês vão procurar palavras que qualificam esse substantivo, [...] que são os adjetivos e as locuções adjetivas. $E$ vão sublinhar também e fazer uma seta pra dizer a que está se referindo [...]. Após fazer isso, vocês vão pegar o caderno de vocês, [...] fazer uma coluna. Uma coluna de substantivos e, do lado, os adjetivos correspondentes, tá?

Fonte: Pinheiro (2018, p. 297)

Assim como Artur, o discurso de Juliana diverge da prática, pois, ao ser questionada na entrevista sobre "O que considera mais relevante abordar no currículo da sua disciplina, no currículo de Português?", a professora responde: "Mais atividades é:: de comunicação e expressão". Da mesma forma, na primeira sessão reflexiva, afirma que trabalha com "a gramática dentro do texto".

As similitudes que perpassam pela relação entre o discurso e a prática dos professores possibilitam-nos inferir que talvez esse quadro seja reflexo não apenas das lacunas encontradas no processo formativo, mas principalmente das concepções de ensino de leitura e da abordagem tradicional de ensino de Língua Portuguesa que ainda permeiam o cotidiano escolar na contemporaneidade, engendrando práticas pedagógicas obsoletas.

O ensino de língua portuguesa, em sua abordagem tradicional, sofreu críticas mais consistentes a partir da década de 1980, por desconsiderar a realidade e o interesse dos alunos, usar o texto como pretexto para o tratamento de aspectos gramaticais, valorizar a gramática normativa e ensinar, de forma descontextualizada, a análise de fragmentos linguísticos com base em exercícios mecânicos (ANTUNES, 2009; SOARES, 2002). A gramática normativa, segundo Possenti (1996), é o tipo mais comum adotado pelos professores de Língua Portuguesa da Educação Básica, aparece com frequência nos livros didáticos e se destina a fazer com que seus leitores aprendam a "falar e escrever corretamente". (POSSENTI, 1996, p. 05). Pode ser definida como um padrão de regras a ser seguido e que garante ao usuário que tais normas, "[...] se dominadas, poderão produzir como efeito, o emprego da variedade padrão (escrita e/ou oral)" (POSSENTI, 1996, p. 05). 
Em função da parca formação que receberam, Artur e Juliana valorizaram mais a gramática normativa, em detrimento de um trabalho centrado no texto enquanto atividade discursiva, por meio da qual os alunos construiriam sentidos e significados, visto que não organizaram a aula com situações funcionais de uso da língua, mas com questões pontuais da gramática, voltadas para fins específicos.

A centralidade da gramática normativa e as práticas tradicionais de ensino de Língua Portuguesa também nortearam a aula de Suzana. Porém, enquanto Artur e Juliana, em sua primeira aula, recorrem ao texto como pretexto para o tratamento gramatical e a aplicação de exercícios, Suzana opta pela aula expositiva, com exemplos no quadro. Sem tomar o texto como unidade básica de ensino e a linguagem enquanto atividade discursiva, a professora revisa o conteúdo sobre advérbios com a intenção de dar continuidade à oração adverbial e, ao final da explicação, aplica um exercício sobre advérbios de modo. Após essa aula, na primeira sessão reflexiva que desenvolvemos com a professora, ela relata como organizou a aula. $O$ excerto do quadro 05 demonstra uma sequência didática centrada da tradição gramatical.

Quadro 05: A gramática é ensinada de forma descontextualizada - dados da 1. a SR com a professora Suzana

\begin{tabular}{|c|l|l|}
\hline \multicolumn{1}{|c|}{ TEMA } & \multicolumn{1}{|c|}{ SENTIDO } & \multicolumn{1}{c|}{ EXEMPLO } \\
\hline $\begin{array}{l}\text { Aspectos curriculares } \\
\text { de Língua Portuguesa }\end{array}$ & $\begin{array}{l}\text { A gramática é ensinada } \\
\text { fe } \\
\text { fescontextualizada }\end{array}$ & $\begin{array}{l}\text { Suzana 17: Então, essa aula, na realidade, foi } \\
\text { uma retomada de conteúdo, porque é, o } \\
\text { planejamento do nono ano, constam lá } \\
\text { algumas questões gramaticais, dentre elas, o } \\
\text { período composto por subordinação e as } \\
\text { orações subordinadas adverbiais. Como é que } \\
\text { eu ia entrar nas adverbiais sem relembrar pra } \\
\text { eles o que é um advérbio, né, trabalhar essa } \\
\text { questão? [...]. Porque faz parte, né, do } \\
\text { planejamento, do currículo, isso faz parte, esse } \\
\text { conteúdo. Aí eu retomei. Meu objetivo era esse. } \\
\text { Lucineide 18: [...] como você pensou em } \\
\text { trabalhar esse conteúdo de advérbios? [...] } \\
\text { Suzana 18: Então, eu pensei numa aula } \\
\text { expositiva, né, com o objetivo de tá retomando } \\
\text { com eles, de uma forma expositiva, porque } \\
\text { como era mesmo pra relembrar, né? De uma } \\
\text { forma, assim, mais superficial [...]. }\end{array}$ \\
\hline
\end{tabular}

Fonte: Pinheiro (2018, p. 304) 
A sessão reflexiva com Suzana revela alguns pontos que queremos discutir: primeiro, é possível observar que a aula da professora segue a prescrição do Currículo do Estado de São Paulo (SÃO PAULO, 2011), quanto ao conteúdo proposto para a série, mas de forma contrária à concepção sociointeracionista da linguagem e sem recorrer à gramática discursiva.

O ensino de Língua Portuguesa deve ter como foco a competência discursiva, que consiste na capacidade do sujeito de utilizar a língua em situações variadas, adequando-a aos diferentes contextos e sentidos, e à modalidade oral ou escrita, por meio das competências linguísticas e epilinguísticas. O professor deve recorrer ao texto como unidade básica de ensino, em vez de sintagmas, frases e palavras descontextualizadas que se distanciam da competência discursiva. Por esse ângulo, o texto constitui-se unidade basilar do processo de ensino-aprendizagem. Karnopp e Pereira (2004) comentam um estudo realizado por Pereira (2002), em que a autora:

Analisou amostras de escrita de alunos surdos pré-escolares, submetidos a um trabalho de linguagem que enfatizou a atividade discursiva e no qual a preocupação não se restringiu à combinação de palavras e frases, mas ao uso da língua, e verificou que eles podem produzir textos ricos em conteúdo e bastante adequados do ponto de vista do português. Segundo a autora, o trabalho com uma língua, seja ela o português ou a língua de sinais, no caso dos alunos surdos, deve focalizar primeiro o uso da língua em diferentes contextos e só depois proceder ao ensino/aprendizado da gramática (KARNOPP; PEREIRA, 2004, p. 36).

O segundo ponto trata-se da justificativa da professora em relação ao conteúdo de advérbios, ao dizer que: "Porque faz parte, né, do planejamento, do currículo, isso faz parte, esse conteúdo", o que demonstra que o currículo de Língua Portuguesa apoia-se na teorização tradicional curricular, isto é, na perspectiva de aceitação, ajuste e conformação da escola às ideologias dominantes com vistas à manutenção do status quo. A professora não questiona o que deve ser abordado na aula porque já recebe o recorte do conhecimento pronto das instâncias administrativas que prescrevem o currículo de Língua Portuguesa, preocupando-se apenas em "como" aplicá-lo e em como estabelecer uma relação de um assunto com o outro. Ou seja, Suzana recebe o recorte e a seleção do currículo pronto e não se pergunta por 
que deve ensinar esse conhecimento. Não há uma reflexão sobre os conteúdos que constam no currículo.

O terceiro ponto que queremos destacar, refere-se à fala de Suzana quanto ao fato de abordar o conteúdo "de uma forma, assim, mais superficial". A forma de tratar o conteúdo desvela que a professora acredita que os alunos surdos não são capazes de aprender como os ouvintes e, por isso, passa a inseri-los em atividades simplificadas de uso da língua, com modificações das atividades cujos objetivos voltam-se apenas para o treino e repetição de elementos gramaticais descontextualizados.

Nesse sentido, Karnopp e Pereira (2004, p. 37) comentam que observam "[...] constantemente adaptações de textos originais por parte do professor, antes de fornecê-los ao aluno, ou textos infantilizados, inadequados aos interesses e à idade dos alunos". Da mesma forma, Vieira (2014) e Müller (2016) demonstram, em suas pesquisas, que atividades infantilizadas voltadas ao suposto aprendizado e livros incompatíveis com a série eram adotados, na educação de surdos, por professores que não acreditavam no potencial desses alunos compreenderem textos longos e desenvolverem atividades complexas.

De acordo com esse contexto, o baixo desempenho escolar passa a ser atribuído ao aluno surdo, e não à estrutura do sistema educacional, que não se adapta para recebê-lo e inseri-lo adequadamente, por meio de práticas pedagógicas bilíngues.

O acesso a práticas linguísticas significativas que os auxiliassem a perceber o sentido na aprendizagem de uma segunda língua, como consequência, as respostas para o fracasso apresentado não foram buscadas nas estratégias inadequadas destinadas ao aprendizado da língua, mas foram justificadas como inerentes à condição da deficiência auditiva e não como possibilidade diferenciada de construção gerada por uma forma de organização linguístico-cognitiva diversa (FERNANDES, 1998, p. 163).

Em síntese, consideramos que a primeira aula de Artur, Juliana e Suzana (quadros 03, 04 e 05), não oferece possibilidades para que os alunos surdos ou ouvintes - apropriem-se das competências básicas da Língua Portuguesa que os permita avançar em estudos posteriores e se constituírem sujeitos de linguagem, pois centra-se em práticas tradicionais que enfatizam o 
caráter técnico de apropriação de elementos gramaticais, distanciando-se, assim, da concepção sociointeracionista da linguagem.

Para os alunos surdos, o tipo de abordagem utilizada pelos professores exerce um impacto negativo ainda maior, visto que a Libras foi desconsiderada em todo o processo. Não houve uma atividade de interpretação e compreensão de texto na qual os surdos, com a mediação do intérprete, dialogassem com o texto, fundamentados nos conhecimentos construídos na língua de sinais. Há apenas uma língua que circula livremente em sala de aula: a Língua Portuguesa. A Libras, nesse caso, é tomada como instrumento de comunicação entre o intérprete e os alunos surdos, não se constituindo enquanto língua de instrução no processo de ensino-aprendizagem da Língua Portuguesa como segunda língua (L2).

Lodi, Harrison e Campos (2015, p. 18) contribuem com essa discussão ao comentarem que:

Embora, muitas vezes, aceite-se a língua de sinais como língua em circulação no ambiente escolar, ela é vista como prática de interação entre pares, para troca de experiências cotidianas e informais, e não como língua em uso para as práticas de ensino. Desvaloriza-se aquilo que o surdo tem a dizer, da forma como o diz. Esclarecemos. A língua de sinais não é considerada como própria para a apropriação dos conhecimentos veiculados social e culturalmente e nem tampouco para se ter acesso à língua portuguesa.

Os dados demonstram ainda que as práticas pedagógicas não se fundamentam na gramática discursiva e nem atentam para os interesses dos alunos. Os surdos, inseridos nesse contexto, são desconsiderados em suas particularidades de aprendizagem. Não há uma língua compartilhada entre professor ouvinte e aluno surdo. O ensino de Língua Portuguesa segue uma abordagem de língua materna para ouvintes, e não de segunda língua (L2) para surdos. Segundo Lissi, Svartholm e González (2012, p. 313):

Abordagens monolíngues na educação de surdos, nas quais a linguagem falada do país é a forma prioritária de comunicação e aquela em que todos os conteúdos escolares são ensinados, colocam várias limitações no processo de ensino para esses alunos. Na maioria dos casos, a criança [ou o adolescente] entra no sistema escolar sem uma linguagem bem 
desenvolvida ao mesmo tempo em que se espera que ela [ele] aprenda os outros conteúdos exigidos no currículo.

As falas dos autores realçam o fato dos alunos surdos, participantes deste trabalho, não serem fluentes em sua primeira língua (L1), a Libras, e terem de aprender uma L2, por meio de uma abordagem de L1 para ouvintes. Sabemos que, no Brasil, a maioria desses alunos chega à escola sem uma língua constituída ou apenas com fragmentos de língua, cabendo à escola a responsabilidade de ensiná-la, concomitantemente ao aprendizado dos conteúdos escolares, desvinculada de uma abordagem adequada e de uma perspectiva bilíngue. Disso decorre, em parte, o quadro de baixo desempenho escolar constatado na educação dos surdos.

\section{Considerações finais}

O ensino de língua portuguesa encontra-se fundamentado no uso social da língua com vistas ao desenvolvimento da competência discursiva, que integra a capacidade do sujeito utilizar a língua em situações diferenciadas, adequando-a ao contexto. Nessa perspectiva, a língua é compreendida como instrumento de comunicação e o texto, unidade básica de ensino, por meio da qual o professor deverá desenvolver sua prática com o objetivo de formar leitores críticos e participativos.

Embora esses princípios sejam defendidos por pesquisadores da Linguística e estejam postos na política nacional de ensino-aprendizagem, as práticas de língua portuguesa para surdos ainda se baseiam na concepção de língua como código e em abordagens tradicionais tanto de currículo como de ensino. Os conhecimentos lexicais e gramaticais são mantidos na posição hegemônica, sendo enfatizados na prática pedagógica como requisitos essenciais que garantem, supostamente, o desenvolvimento das competências de leitura e escrita. Tal situação decorre em razão das práticas tradicionais de ensino estarem, de certo modo, tão arraigadas que, mesmo depois de conhecerem subjetivamente outra abordagem, os professores não sabem como desenvolvê-la, visto que não receberam formação apropriada.

Dadas às lacunas na formação docente, é comum os professores desenvolverem aulas homogêneas, como se não houvesse alunos surdos em sala de aula. A abordagem utilizada pelos professores pauta-se no ensino de 
primeira língua para ouvintes, e não de segunda língua para surdos, desconsiderando, assim, a especificidade linguística e de aprendizagem desses alunos. A língua de sinais é desvalorizada, uma vez que não lhe é atribuída status de língua, pois, se assim o fosse, haveria esforços de vários níveis para integrá-la à concepção de ensino bilíngue, direcionada aos princípios da inclusão escolar.

Além disso, quanto à metodologia, os professores recorrem às aulas expositivas, usam o texto como pretexto para o tratamento de elementos gramaticais descontextualizados e aplicam exercícios ao final da aula como forma de "avaliar" ou "reforçar" o aprendizado do aluno. Essas práticas retratam que o ensino de Língua Portuguesa ainda se encontra fundamentado em aspectos da comunicação total e do oralismo. Ambas as abordagens se apresentam com outra aparência e permanecem submetendo o surdo a um forçoso processo de aprendizado da língua portuguesa, sem sucesso, e ocultando a Língua Brasileira de Sinais das práticas pedagógicas.

A Libras tem de ser legitimada no ambiente escolar como língua de comunicação e de instrução. A oferta de práticas bilíngues é direito dos surdos. Segundo Vygotsky ([1934] 2009, p. 398), “[...] a linguagem não é só instrumento de comunicação, mas também de pensamento [...]". Ela é elemento central no desenvolvimento dos processos cognitivos e na apropriação cultural.

\section{Referências}

ANTUNES, Irandé. Língua, texto e ensino: outra escola é possível. São Paulo: Parábola Editorial, 2009.

BRASIL. Lei n. 10.436, de 24 de abril de 2002. Dispõe sobre a Língua Brasileira de Sinais - Libras e dá outras providências. Diário Oficial da União, Brasília, 25 abr. 2002. Disponível em: http://www.planalto.gov.br/ ccivil_03/Leis/2002/L10436.htm. Acesso em: 28 jan. 2015.

BRASIL. Decreto-lei n. 5.626, de 22 de dezembro de 2005. Regulamenta a lei $n$. 10.436, de 24 de abril de 2002, que dispõe sobre a Língua brasileira de sinais Libras, e o art. 18 da Lei n. 10.098, de 19 de dezembro de 2000. Diário Oficial da União, Brasília, DF, 23 dez. 2005. Disponível em: 
http://www.presidencia.gov.br/ccivil_03/_Ato2004-2006/2005/Decreto/ D5626.htm. Acesso em: 15 out. 2010.

BRASIL. Ministério da Educação. Secretaria da Educação Básica. Base nacional comum curricular. Brasília, DF, 2016. Disponível em:

http://basenacionalcomum.mec.gov.br/\#/site/inicio. Acesso em: jul. 2020.

BRASIL. Lei no 13.415, de 16 de fevereiro de 2017. Altera as Leis nos 9.394, de 20 de dezembro de 1996, que estabelece as diretrizes e bases da educação nacional, e 11.494, de 20 de junho 2007, que regulamenta o Fundo de Manutenção e Desenvolvimento da Educação Básica e de Valorização dos Profissionais da Educação, a Consolidação das Leis do Trabalho CLT, aprovada pelo Decreto-Lei no 5.452, de 1 o de maio de 1943, e o Decreto-Lei no 236, de 28 de fevereiro de 1967; revoga a Lei no 11.161, de 5 de agosto de 2005; e institui a Política de Fomento à Implementação de Escolas de Ensino Médio em Tempo Integral. Portal da Legislação, Brasília, 16 fev. 2017. Disponível em: http://www.planalto.gov.br/ccivil_03/_Ato2015-2018/2017/Lei/L13415.htm. Acesso em: 31 jul. 2017.

BRITO, Fábio. O movimento social surdo e a campanha pela oficialização da língua brasileira de sinais. 2013. 275 f. Tese (Doutorado em Educação) Faculdade de Educação, Universidade de São Paulo, São Paulo, 2013.

BRONCKART, Jean-Paul. Atividade de linguagem, discurso e desenvolvimento humano. Campinas: Mercado de Letras, 2006.

CAMPOS, Sandra Regina. Onde começa a educação bilíngue para surdos? In: GARRUTI-LOURENÇO, Érica Aparecida (Org.). Educação Bilíngue para Surdos Série Cadernos de Residência Pedagógica. São Paulo: Alameda, 2017. p. 43-57.

FERNANDES, Sueli. Surdez e linguagens: é possível o diálogo entre as diferenças? 1998. 216 f. Dissertação (Mestrado em Estudos Linguísticos) Universidade Federal do Paraná, Curitiba, 1998. 
FERNANDES, Eulália.; CORREIA, Manoel. Bilinguismo e surdez: a evolução dos conceitos no domínio da linguagem. In: FERNANDES, Eulália (Org.). Surdez e bilinguismo. Porto Alegre: Mediação, 2015. p. 5-25.

GUARINELLO, Ana. O papel do outro na escrita de sujeitos surdos. São Paulo: Plexus, 2007.

KARNOPP, Lodenir.; PEREIRA, Maria. Concepções de leitura e escrita e educação de surdos. In: LODI, Ana Cláudia.; HARRISON, Kathryn.; CAMPOS, Sandra (Orgs.). Leitura e escrita no contexto da diversidade. Porto Alegre: Mediação, 2004. p. 33-38.

LACERDA, Cristina. A prática pedagógica mediada (também) pela língua de sinais: Trabalhando com sujeitos surdos. Cad. CEDES, Campinas, ano XX, no 50, p. 70-83, abril 2000. Disponível em:

https://www.scielo.br/pdf/ccedes/v20n50/a06v2050.pdf. Acesso em: 31 jul. 2020.

LISSI, María; SVARTHOLM, Kristina.; GONZÁLEZ, Maribel. Enfoque bilíngue na educação de surdos: implicações para o ensino e aprendizagem da língua escrita. Revista Estudos Pedagógicos, Valdivia (Chile), v. 38, n. 2, p. 299-320, dez. 2012, p. 313. Disponível em: http://www.scielo.cl/scielo.php? pid $=$ S071807052012000200019\&script=sci_abstract\&tlng=p. Acesso em: 3 jun. 2020.

LODI, Ana Cláudia.; HARRISON, Kathryn.; CAMPOS, Sandra. Letramento e surdez: um olhar sobre as particularidades do contexto educacional. In: LODI, Ana Cláudia.; MÉLO, Ana Dorziat.; FERNANDES, Eulália. (Orgs.). Letramento, bilinguismo e educação de surdos. 2. ed. Porto Alegre: Mediação, 2015, p. 18

MAGALHÃES, Maria Cecília. A etnografia colaborativa: pesquisa e formação profissional. In: FIDALGO, Sueli.; SHIMOURA, Alzira (Orgs.). Pesquisa crítica de colaboração: um percurso na formação docente. São Paulo: Ductor, 2006. p. 56-63. 
MARCUSCHI, Luiz Antônio. Produção textual, análise de gêneros e compreensão. São Paulo: Parábola Editorial, 2008.

MATOS, Daniela. $O$ ensino da Língua Portuguesa escrita para a criança surda em uma perspectiva bilíngue. 2017. 199f. Dissertação (Mestrado em Educação e Saúde na Infância e na Adolescência) - Programa de Pós-Graduação em Educação e Saúde na Infância e na Adolescência), Universidade Federal de São Paulo, Guarulhos, 2017.

MÜLLER, Janete. Língua portuguesa na educação bilíngue de surdos. 2016. 295f. Tese (Doutorado em Educação) - Universidade Federal do Rio Grande do sul - UFRGS, Porto Alegre, 2016.

PEREIRA, Maria Cristina. Leitura, escrita e surdez. São Paulo: FDE, 2009.

PEREIRA, Maria Cristina. O ensino de português como segunda língua para surdos: princípios teóricos e metodológicos. Educar em Revista, Curitiba, n. 2, p. 143-157, 2014. Disponível em: http://www.scielo.br/pdf/er/nspe-2/11.pdf. Acesso em: 27 abr. 2020.

PEREIRA, Maria Cristina. Ensino da língua portuguesa para surdos. São Paulo: Núcleo de Educação a Distância da Unesp/AVA Moodle [Edutec], 2015. Curso de Especialização em Educação Especial na área de Deficiência Auditiva da Rede São Paulo de Formação Docente. Disponível em:

https://acervodigital.unesp.br/bitstream/unesp/252175/1/unespnead_reei1_ee_d11_da_texto1.pdf. Acesso em: 15 fev. 2017.

PINHEIRO, Lucineide. Adaptações curriculares na "inclusão" escolar de alunos surdos: intervenções colaborativas. 2018. 430f. Tese (Doutorado em Ciências: Educação e Saúde na Infância e na Adolescência) - Universidade Federal de São Paulo, Unifesp, 2018.

PINHEIRO, Lucineide; FIDALGO, Sueli. Adaptações curriculares na "inclusão" escolar de alunos surdos: intervenções colaborativas. Revista Brasileira da Pesquisa Sócio-Histórico-Cultural e da Atividade, v. 1, n. 1, p. 1-15, 2019. 
POSSENTI, Sírio. Por que (não) ensinar gramática na escola. Campinas:

Mercado de Letras - Associação de Leitura no Brasil, 1996. Disponível em: https://zellacoracao.files.wordpress.com/2009/03/porquenao_ensinar_gramatica_escola.pdf. Acesso em: 3 maio 2020. PRETI, Dino. Análise de textos orais. São Paulo: Humanitas, 1999.

QUADROS, Ronice. Educação de surdos: a aquisição da linguagem. Porto Alegre: Artmed, 1997.

SÃO PAULO (Estado). Secretaria da Educação. Currículo do Estado de São Paulo: Linguagens, códigos e suas tecnologias. São Paulo: SE, 2011. 260p.

SCHÖN, Donald. Formar professores como profissionais reflexivos. In: NÓVOA, A. (org.). Os professores e a sua formação. Lisboa: Publicações Dom Quixote, 1995. p. 77-91.

SOARES, Magda. Português na escola: história de uma disciplina curricular. In: BAGNO, Marcos (Org.). Linguística da norma. São Paulo: Loyola, 2002. p. 155177.

UNESCO. Declaração de Salamanca e Enquadramento da Ação na Área das Necessidades Educativas Especiais. Conferência Mundial sobre Necessidades Educativas Especiais: acesso e qualidade. Salamanca, Espanha, 7 a 10 de junho, 1994.

VIEIRA, Cláudia. Bilinguismo e inclusão: problematizando a questão. Curitiba: Appris, 2014.

VYGOTSKY, Lev Semyonovich. Las raíces genéticas del pensamiento y el lenguaje. In: VYGOTSKI, L. S. (org.). Obras escogidas II: pensamiento y lenguaje - conferencias sobre psicología. Madrid (Espanha): Visor, 1934/2001. p. 91-118.

VYGOTSKY, Lev Semyonovich. A construção do pensamento e da linguagem. São Paulo: Martins Fontes, 1934/2009. 